Research Article

\title{
Biogenic Synthesis, Characterization of Silver Nanoparticles from Candelula Officinalis Extract and Evaluation of their Antimicrobial Activity
}

\author{
Rashmi Arora, Anita Grewal \\ Department of Biotechnology, University Institute of Engineering and Technology, Kurukshetra University, Kurukshetra-136119, \\ Haryana, India
}

$\triangle$ Corresponding author: E-mail: anitapunia_17@rediffmail.com

Received: Apr. 28, 2015; Accepted: Jun. 9, 2015; Published: Jun. 18, 2015.

Citation: Rashmi Arora and Anita Grewal. Biogenic Synthesis, Characterization of Silver Nanoparticles from Candelula Officinalis Extract and Evaluation of their Antimicrobial Activity. Nano Biomed. Eng. 2015, 7(2), 47-5I.

DOI: $10.5101 /$ nbe.v7i2.p47-5I.

\begin{abstract}
Synthesis of silver nanoparticles from root extract of Candelula officinalis (marigold) as a biomaterial is reported in the present study. Plant root extract has water soluble organic materials which help in the reduction of silver ions and stabilization of AgNPs. Aqueous solution of silver nitrate was treated with root extract of $C$. officinalis for the formation of AgNPs. The UV-Visible spectroscopy indicated an absorption peak at $423 \mathrm{~nm}$, which indicates synthesis of AgNPs. Further characterization by Dynamic Light Scattering (DLS) showed size distribution profile of synthesized silver nanoparticles (AgNPs). Transmission electron microscopy (TEM) demonstrated the presence of spherical AgNPs in range of 14-40 nm. The formed silver nanoparticles showed good antimicrobial activity against various microorganisms viz. Eshcherichia coli, Pseudomonas aeruginosa, Bacillus subtilis, Candida albicans. AgNPs showed the maximum activity against Pseudomonas aeruginosa with a inhibition zone of $22 \mathrm{~nm}$. Thus, the present study provides evidence of simple, rapid and environmental friendly route to synthesize AgNPs using aqueous root extract of Candelula officinalis.
\end{abstract}

Keywords: Silver nanoparticles; Candelula officinalis; TEM; DLS; UV-Vis; Antimicrobial activity

\section{Introduction}

Nanotechnology deals with the production, manipulation, and use of material that ranges from less than a micron in size. A nanometer is 1 billionth of a meter or roughly the length of 3 atoms side by side [1]. Bionanotechnology on the whole deals with the interaction of biology, chemistry, material sciences, engineering, and medicine. Silver nanoparticles are of immense use due to their size, catalytic properties, and antimicrobial behavior [2]. Remarkable advances are made in the field of biotechnology and nanotechnology to harness the benefit of life sciences, health care and industrial biotechnology [3, 4]. Nanomaterials may provide solutions to technological and environmental challenges in the areas of solar energy conversion, catalysis, medicine and water treatment [5]. This increasing demand must be accompanied by "green" synthesis methods. The green synthesis of nanoparticles, on the other hand, concerns the transformation of biological systems to create new devices on a nanoscale. These are produced through 
various physical and chemical processes however, all of these methods have detrimental effects due to increased size, high energy and capital investment requirements, and the use of toxic chemicals [6, 7]. Keeping in view the disadvantages entailed in both processes, we have adopted biogenic methods for the synthesis of AgNPs. These methods are clean and less expensive, require less energy, and employ ambient conditions [8]. There are many examples of synthesizing silver nanoparticles using plant/plant extract because they posssess large variety of metabolites like terpenoids, flavones, aldehydes, ketones etc for the bioreduction involved in biosynthesis [9]. Silver has long been recognized as having inhibitory effect on microbes. Ag NPs are supposed to be the new generation of antimicrobials as they are being used in many antimicrobial preparations [10], therapeutics [11] and pharmaceutical applications [12] antiviral and HIV studies [13] applications.

Candelula officinalis (Marigold) is a common garden herb which belongs to family Asteraceae. Calendula officinalis is a good source of natural antioxidants, which contains many different radical scavenger components providing protection against harmful-free radicals. It is used for the treatment of inflammation and skin wounds [14, 15]. It is having medicinal importance due to presence of oleanolic acid which provide health benefits, protective effects against the development of cancer, chemotherapy and radiation therapy adverse effects, inhibition of existing tumour cells, anti-inflammatory activity and antioxidant activity [16]. Thus, we report here synthesis, characterization and antibacterial activity of AgNPs using root extract of Candelula officinalis.

\section{Materials and Methods}

\section{Preparation of Plant Extracts}

The roots of Calendula officinalis (marigold) collected from the campus of Kurukshetra University, Kurukshetra were thoroughly washed several times with running water to remove the dust particles. They were placed in a hot air oven for drying at $70^{\circ}$ overnight for 4-5 days. Dried parts were ground to fine powder and used for preparing the plant extract. The extract was prepared by taking $20 \mathrm{~g}$ of powder in 100 $\mathrm{ml}$ deionized water in a $250 \mathrm{ml}$ of conical flask. This mixture was boiled for $10 \mathrm{~min}$. using hot plate and filtered with whattman No.1 filter paper. The extract was preserved inside a refrigerator for future use. Then the solution was used for the reduction of silver ions $\left.\mathrm{Ag}^{+}\right)$to silver nanoparticles $\left(\mathrm{Ag}^{\circ}\right)$.

\section{Cultures}

Escherichia coli (MTCC No. 40), Bacillus subtilis (MTCC No. 441), Candida albicans (MTCC No. 3017), Pseudomonas aeruginosa (MTCC No. 424) used for antimicrobial assay of AgNPs were obtained from IMTECH, Chandigarh. India.

\section{Synthesis of silver nanoparticles}

Still up to date there is no proposed mechanism for the synthesis of silver nanoparticles. The hypothetical method behind synthesis is an enzymatic reaction in which plant extract contains the complex of reducing enzymes which reduce the chemicals such as silver nitrate into silver ions and nitrate ions. Silver nitrate solution of $(1 \mathrm{mM})$ was prepared and used for synthesis of silver nanoparticles. $4 \mathrm{ml}$ of plant extract was added to $16 \mathrm{ml}$ solution of $1 \mathrm{mM} \mathrm{AgNO}$ for reduction into $\mathrm{Ag}^{+}$ions, incubated at $80{ }^{\circ} \mathrm{C}$ in a water bath for 10 mins. The colour of the solution changed to brown red indicating the synthesis of silver nanoparticles.

\section{Characterization of silver nanoparticles}

\section{UV-Visible spectroscopic analysis}

UV-Vis absorption spectroscopy is the branch of spectroscopy where the absorption of light by molecules that are in a gas or vapor state or dissolved molecules/ions can be measured. It investigates the absorption between the wavelength limits $190 \mathrm{~nm}$ and $1100 \mathrm{~nm}$ where absorption of the electromagnetic radiation is caused by the excitation of bonding and non bonding electrons of the ions or molecules. The reduction of metallic $\mathrm{Ag}^{+}$ions was observed by subjecting small aliquots from the reaction mixture for measurement of the absorbance by UV-Visible spectrophotometer which showed absorption peak at $423 \mathrm{~nm}$ that indicates the synthesis of silver nanoparticles.

\section{Transmission electron microscopy}

TEM uses an electron beam to prepare an image of a sample. High energy electron beam falls upon ultrathin samples allow for image resolutions that are of the order of 1-2 $\mathrm{A}^{\circ}$. Scanning under TEM (Philips CM-10) was done to find out shapes and sizes of synthesized silver nanoparticles (AgNPs). 


\section{Dynamic light scattering}

The Dynamic light scattering (DLS) or photon correlation spectroscopy method was used to obtain the size distribution profile of nanoparticles present in suspension or solution. Dynamic Light Scattering Analyzer is required for DLS analysis.

\section{Evaluation of antibacterial activity}

Effect of biosynthesized silver nanoparticles was analyzed against human pathogens by agar well diffusion method. In this method, three wells were cut in nutrient agar plates with the help of sterile $1 \mathrm{ml}$ tips. Pathogens (Bacillus subtilis, Staphylococcus aureus, Pseudomonas aeruginosa, Escherichia coli, Candida albicans) were spread on agar plates by spread plate method. After that, in one well 2 to $20 \mu 1$ plant extract was filled. 2nd well was filled with $\mathrm{AgNO}_{3}$ (Positive control) and 3rd well was filled with the mixture of $\mathrm{AgNO}_{3}$ and extract. Then, the plates were incubated at $37{ }^{\circ} \mathrm{C}$ for $24 \mathrm{~h}$. After incubation, the zones of inhibition were measured and activities were evaluated by increase in fold area activity.

\section{Results and discussion}

The reduction of silver ions into silver particles following exposure to plant extracts could be deciphered by a change in color. Synthesised silver nanoparticles of $C$. officinalis in the present study exhibited a dark yellowish color initially when the extract was treated with $\mathrm{AgNO}_{3}$ in ratio of $4: 1$ but changed to brownish red after incubation at $80{ }^{\circ} \mathrm{C}$ in water bath for 10 minutes (Fig. 1). The reason for colour change was the excitation of Surface Plasmon vibrations in metal nanoparticles [17, 11]. Optical absorption spectroscopy has proved to be a very useful technique for the analysis of nanoparticles.

In order to verify the synthesis of AgNPs, the test samples were subjected to UV-vis spectrophotometric analysis. The test sample (root extract treated with $1 \mathrm{mM}$ of $\mathrm{AgNO}_{3}$ ) was collected in aliquots from the reaction mixture and analysed to record their absorbance by UV-vis spectrophotometer. This analysis showed the sharp absorbance at around 423 nm (Fig. 2), which was specific for AgNPs [18, 19]. $\mathrm{Li}$ et al. [20] reported similar results, in which they observed that when sun-dried leaf extracts of Capsicum were challenged with aqueous silver ions, the reaction mixture containing AgNPs showed the absorption peak at about $420 \mathrm{~nm}$ due to the excitation of plasmon resonance vibration. Similarly TEM Analysis was done to find out the shape and size of biosynthesized silver nanoparticles in solution. TEM images of AgNPs revealing the average mean size of 14-40 nm (Fig. 3). It was observed that most of the $\mathrm{Ag}$ nanoparticles were spherical in shape in addition there are agglomerated

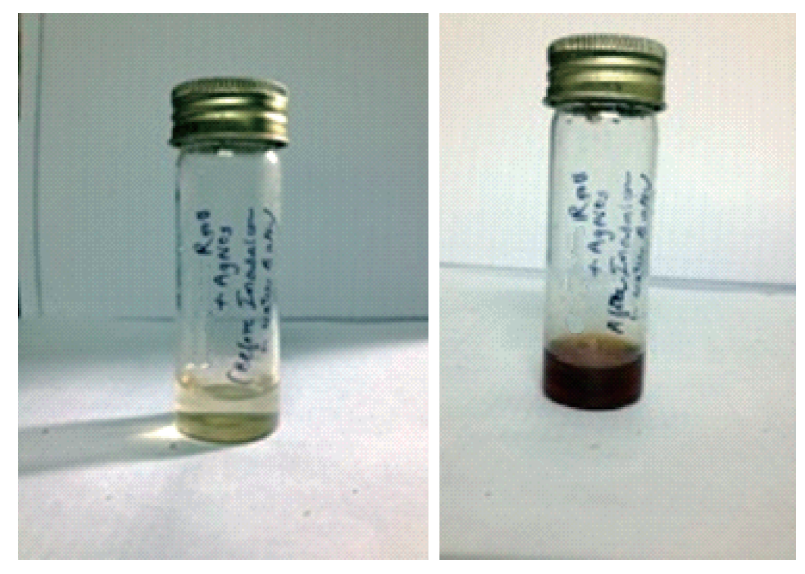

Fig. 1 Change in colour of root extract of C. officinalis from transparent to reddish brown after treatment with $1 \mathrm{mM}$ of $\mathrm{AgNO}_{3}$ solution.

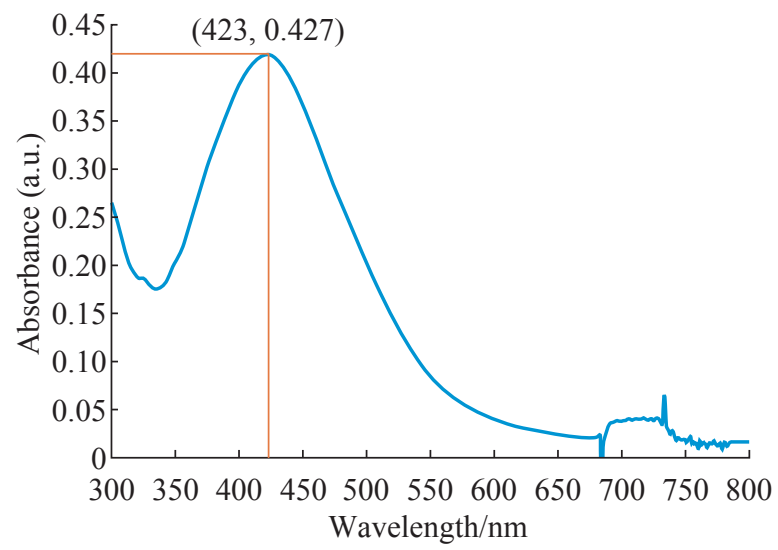

Fig. 2 Uiv-Vis Absorption spectrum for silver nanoparticles synthesized by Calendula officinalis (marigold) root extract showing absorbance at $423 \mathrm{~nm}$.

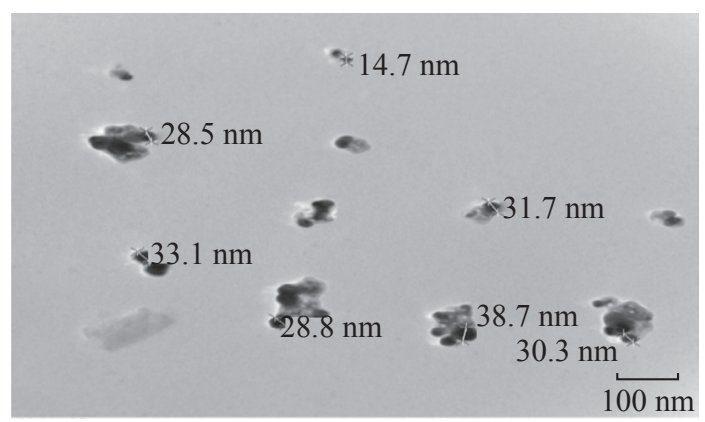

Fig. 3 TEM images and size distribution of silver nanoparticles synthesized by reduction of $\mathrm{AgNO}_{3}$ with $C$. officinalis (Scale bar $-100 \mathrm{~nm})$. 


$\begin{array}{rllll} & & \text { Size (d.nm) } & \text { Intensity (\%) } & \text { Width (d.nm) } \\ \text { Z-Average (d.nm): } 84.33 & \text { Peak 1: } & 87.34 & 96.4 & 31.14 \\ \text { PdI: } 0.414 & \text { Peak 2: } & 5294 & 3.6 & 407.2 \\ \text { Intercept: } 0.918 & \text { Peak 3: } & 0 & 0 & 0\end{array}$

Result quality: Good

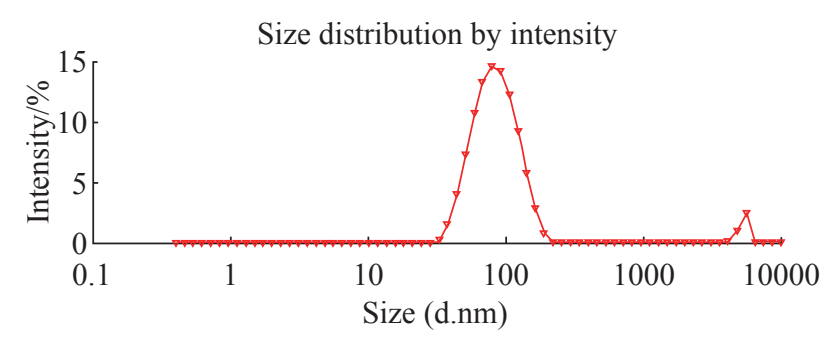

Fig. 4 Graph between intensity (\%) of light scattered from particles in suspension v/s diameter of silver nanoparticle synthesized from C. officinalis in nm.

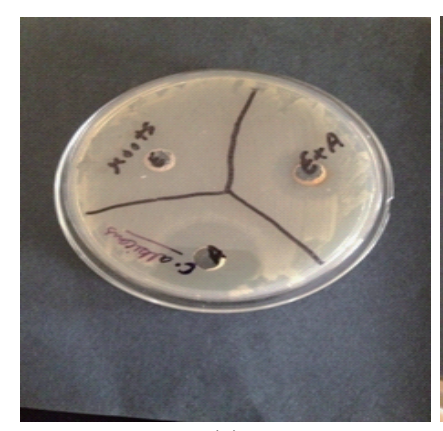

(a)

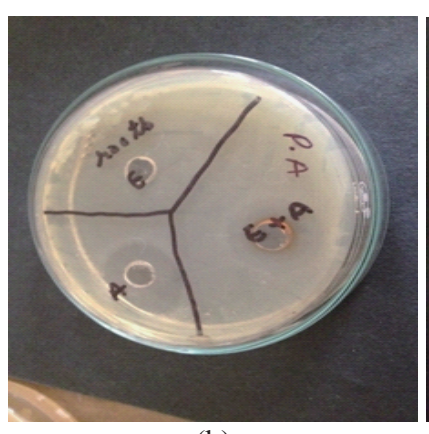

(b)

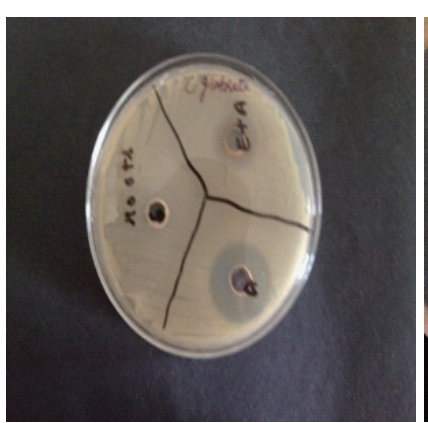

(c)

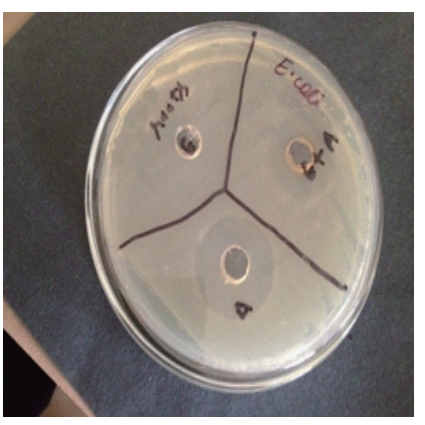

(d)

Fig. 5 Plates showing antimicrobial activity of AgNPs synthesized by Calendula officinalis (marigold) roots extract against $C$. albicans (a) and P. aeruginosa (b) Bacillus (c) and E. coli (d). (A: $\mathrm{AgNO}_{3}$, E: Plant extract, A+ E: AgNPs).

silver nanoparticles, indicating possible sedimentation at a later time. Further FTIR analysis may be used to identify and to get an approximate idea of the possible biomolecules that are responsible for the reduction and stabilization of the AgNPs. Dynamic light scattering or Photon Correlation Spectroscopy is a technique used in material physics for determining the size distribution profile of metal based nanoparticles in solution. The study revealed that the average particle size of $\mathrm{Ag}$ nanoparticles synthesized from Candelula officinalis (marigold) root extract was in range of 40-400 nm with average size of approximately 80-90 nm (Fig. 4).

\section{Antimicrobial Activity of $C$. officinalis AgNPs}

The antimicrobial activity of silver has been recognized by clinicians for over 100 years due to their growth inhibitory capability against microorganisms. The nanoparticles synthesized were used for antimicrobial activity against Bacillus subtilis, Pseudomonas aeruginosa, Escherichia coli, Candida albicans, it was found that the highest inhibition was against $P$. aeruginosa with a inhibition zone of $22 \mathrm{~mm}$ (Fig. 5) whereas lowest was revealed against $B$. subtilis. These findings substantiate with the findings in which $S$. aureus showed the maximum sensitivity to Ag NPs, whereas E. coli was less sensitive [21]. Similarly, phytosynthesis of silver nanoparticles using Pterocarpus santalinus leaf extract and their antibacterial properties are also reported [22]. It is suggested that the antibacterial effect of Ag nanoparticles is associated with the peptidoglycan layer, although the precise mechanism of the inhibitory effects on microorganisms is not clear. Some have suggested that the positive charge on the Ag ion is crucial for antibacterial activity due to electrostatic attraction between the negatively charged cell membrane of the microorganism and the positively charged nanoparticles [23, 24]. There is an accumulation of $\mathrm{Ag}$ nanoparticles in the bacterial membrane causing an alteration in permeability, which results in cell death.

\section{Conclusions}

It has been proved from above experiment that 
root extract from candelula officinalis is capable of synthesizing silver nanoparticles extracellularly. Thus, it is an economic, quick, simple and environment friendly technique. Also Silver nanoparticles have several characteristics that make it currently among the most widely used nanoparticle in science. The characterization from UV-Vis, TEM, DLS support the stability of the biosynthesized nanoparticles. UV-vis spectra for Calendula officinalis (marigold) roots denoted a peak at 418 nm. TEM analysis of silver nanoparticles synthesized in present investigation confirmed the presence of spherical shaped nanoparticles in the size range of $40 \mathrm{~nm}$. It may be inferred that root is the most relevant source for the extracellular synthesis of bionanoparticles. The great tendency of silver nanoparticles towards the toxicity for bacteria made them a good option for bio-medicinal applications.

\section{References}

[1] N. Kannan, S. Subbalaxmi. Biogenesis of nanoparticles - a current prospective. Rev Adv Mater Sci., 2010, 27: 99-114.

[2] H.B. Kushwaha, C.P. Malik. Biopotential of Verbesina encelioides (stem and leaf powders) in silver nanoparticle fabrication. Turkish J. Biol., 2013, 37: 654-654.

[3] J.L. Torresdey, J.G. Parsons, E. Gomez, et al., Formation and growth of $\mathrm{Au}$ nanoparticles inside live alfalfa plants. Nano Lett., 2002, 2: 397-401.

[4] S.Y. Yeo , H.J. Lee, S.H Jeong. Antibacterial effect of nanosized of silver colloidal solution on textile fabrics. $J$. Mater Sci., 2003, 38: 2199-2003.

[5] J.E. Hutchison. Greener nanoscience: a proactive approach to advancing applications and reducing implications of nanotechnology. ACS Nano., 2008, 2: 395.

[6] V. Parashar, R. Parashar, B. Sharma, A.C. Pandey. Parthenium leaf extract mediated synthesis of silver nanoparticle: a novel approach for weed utilization. Dig. J. Nanomater. Bios., 2009, 4: 45-50.

[7] D.P. Gnanadhas, M.B. Thomas, M.R. Ashok, et al., Interaction of Silver Nanoparticles with Serum Proteins Affects Their Antimicrobial Activity. In Vivo Antimicrob. Agents Chemother., 2013, 57: 4945-4955.

[8] A. Saxena, R.M. Tripathi, R.P. Singh. Biological synthesis of silver nanoparticles by using onion (Allium cepa) extract and their antibacterial activity. Dig. J. Nanomater. Bios., 2010, 5: 427-432.

[9] H. Kaur, S. Kaur, M. Singh. Biosynthesis of silver nanoparticles by natural precursor from clove and their antimicrobial activity. Biologia., 2013, 68(6): 1048-1053.

[10] M.K. Rai, A.P. Yadav, A.K. Gade. Silver nanoparticles as a new generation of antimicrobials. Biotechnol. Adv.,
2009, 27(1): 76-82.

[11] B. Mahitha, B.D.P. Raju, G.R. Dillip, et al., Biosynthesis, characterization and antimicrobial studies of AgNPs extract from Bacopa monierra whole plant. Digest J. Nanomat. Biostr., 2011, 6(1): 135-142.

[12] S.R. Bonde, D.P. Rathod, A.P. Ingle, et al., Murraya koenigii-mediated synthesis of silver nanoparticles and its activity against three human pathogenic bacteria. Nanoscience Methods, 2012, 1: 25-36.

[13] N. Duran, P.D. Marcarto, G.I.H. De Souza, et al., Esposito J Biomed Nanotechnol, 2007, 3: 203-208.

[14] J.L. Elechiguerra, J.R. Morones, A. Camacho-Bragado, et al. Interaction of nanoparticles with HIV-1. J. Nanobiotechnol. 2005, 3: 6.

[15] I.R. Bunghez, R.M. Ion. Complex spectral characterization of active principles from marigold (Calendula Officinalis). J. Sci. Art., 2011, 14: 59-64.

[16] I. Fierascu, I.R. Bunghez, R. Fierascu, et al., Characterization and antioxidant activity of photosynthesised silver nanoparticles using C. officinalis extract. Farmacia. 2014, 62(1): 129-136.

[17] M. Butnariu, I.C. Zepa. Coradin. Evaluation of biologically active compounds from Calendula officinalis flowers using spectrophotometry. Chem. Cent., 2012, 6: $1-7$.

[18] S. Ankanna, T.N.V.K.V. Prasad, E.K. Elumalai, et al., Production of biogenic silver nanoparticles using Boswellia ovalifoliolata stem bark. Digest J. Nanomat. Biostr., 2010, 5(2): 369-372.

[19] K. Mallikarjuna , G. Marasimha , G.R. Dillip, et al., Green synthesis of silver nanoparticles using Ocimum leaf extract and their characterization. Digest J. Nanomat. Biostr., 2011, 6: 181-186.

[20] J. Huang, C. Chen, N. He, et al., Biosynthesis of silver and gold nanoparticles by novel sun dried Cinnamum camphora leaf. Nanotechnology, 2007, 18: 105-106.

[21] S. Li , Y. Shen , A. Xie , et al., Green synthesis of silver nanoparticles using Capsicum annum L. extract. Green Chem., 2007, 9: 852-872.

[22] A.R. Shahverdi, A. Fakhimi, H.R. Shahverdi, et al., Synthesis and effect of silver nanoparticles on the antibacterial activity of different antibiotics against $\mathrm{S}$. aureus and E. coli. Nanomedicine, 2007, 3: 168-171.

[23] K. Gopinath, S. Gowri, A. Arumugam. Phytosynthesis of silver nanoparticles using Pterocarpus santalinus leaf extract and their antibacterial properties. J. Nanostr. Chem., 2013, 3: 1-7.

[24] P. Dibrov, J. Dzioba, K.K. Gosink. Chemiosmotic mechanism of antimicrobial activity of $\mathrm{Ag}(+)$ in Vibrio cholerae. Antimicrobial Agents Chemotherapy, 2002, 46: 2668-2670.

[25] A.K. Gade, P. Bonde, A.P. Ingle, et al., Exploitation of Aspergillus niger for synthesis of silver nanoparticles. Biobased. Mater. Bioenergy, 2008, 2(3): 1-5.

Copyright $($ C 2015 Rashmi Arora and Anita Grewal. This is an open-access article distributed under the terms of the Creative Commons Attribution License, which permits unrestricted use, distribution, and reproduction in any medium, provided the original author and source are credited. 